\title{
Article \\ Edible Flowers' Antioxidant Properties and Polyphenols Content Reflect Their Applicability for Household and Craft Tincture Production
}

\author{
Maria Śmiechowska (D), Przemysław Dmowski * and Larysa Skowierzak \\ Department of Commodity Science and Quality Management, Gdynia Maritime University, Morska 81-87 \\ 81-225 Gdynia, Poland; m.smiechowska@wznj.umg.edu.pl (M.Ś.); larysajagielska@gmail.com (L.S.) \\ * Correspondence: p.dmowski@wznj.umg.edu.pl; Tel.: +48-58-5586-257
}

check for

updates

Citation: Śmiechowska, M.; Dmowski, P.; Skowierzak, L. Edible Flowers' Antioxidant Properties and Polyphenols Content Reflect Their Applicability for Household and Craft Tincture Production. Appl. Sci. 2021, 11, 10095. https://doi.org/ 10.3390/app112110095

Academic Editors: Ewelina Hallmann and Maria Kanellaki

Received: 28 July 2021

Accepted: 21 October 2021

Published: 28 October 2021

Publisher's Note: MDPI stays neutral with regard to jurisdictional claims in published maps and institutional affiliations.

Copyright: (c) 2021 by the authors. Licensee MDPI, Basel, Switzerland. This article is an open access article distributed under the terms and conditions of the Creative Commons Attribution (CC BY) license (https:// creativecommons.org/licenses/by/ $4.0 /)$.
Featured Application: The suitability of individual colour parameters of the CIE $L^{*} a^{*} b^{*}$ system for identifying alcoholic tinctures of edible flowers in terms of production method has been demonstrated.

\begin{abstract}
The growing interest of consumers in regional and traditional products drew our attention to innovative products manufactured at home and using craft methods, which include, among others, alcohol tinctures of edible flowers. The aim of this paper is to present selected tinctures of edible flowers from home and craft production, their phenol content, antioxidant properties and colour. Novel alcoholic beverages obtained from edible flowers are characterized. The tinctures from wild rose flowers, elderberry, marigold and cornflower were studied. The content of phenolic compounds, the antioxidant properties and the colour of tinctures in the CIE L*a*b* system were analysed. The study showed that edible flower tinctures are characterized by an intense colour, which is not adversely affected by the maceration process. The determined parameters were influenced by the form of flowers (fresh or dried). The total content of polyphenolic compounds and antioxidant activity in the studied tinctures were lower than in the fresh flowers. Edible flower tinctures can be an interesting alternative for both consumers looking for product innovations and alcohol connoisseurs.
\end{abstract}

Keywords: edible flowers; tinctures; edible flowers; antioxidant properties; polyphenols; colour

\section{Introduction}

Tinctures are a category of traditional alcoholic beverages, often produced regionally, locally, and at home. The popularity of tinctures, especially those related to a specific geographical region, has been raised due to tourism and to consumers' desire to familiarize themselves with new products. Tinctures are usually made by pouring various alcohols or diluted spirits over the edible parts of plants, mainly fruits and seeds [1]. This type of obtaining alcoholic extracts is known as maceration and is often found in pharmaceutical practice to obtain extracts of medicinal herbs [2].

Alcoholic beverages in various forms have been known and produced for centuries. Tinctures and liqueurs are categories of alcoholic beverages produced in many countries, including Poland. Most often they are prepared by pouring various types of alcohol or diluted spirit over the fruit and seeds. The most famous liqueurs include banana liqueur, almond liqueur (Amaretto), kumquat liqueur from Corfu, lemon liqueur (Limoncello), nut liqueur (Nocino) and multifruit liqueurs [3-8]. Renowned tinctures include Eastern European tinctures such as Karlovarska Becherovká, Jägermeister, and Underberg, which are herbal tinctures with recognized values [9].

In addition to taste and aroma, tinctures, especially herbal ones, possess medicinal properties and have been used in treating various diseases and in cosmetology for centuries [4]. In the search for new raw materials for the production of alcoholic products, 
attention has been paid to edible flowers, which have been recently gaining importance and are primarily used in their fresh form to decorate dishes and servings [10,11]. Until recently, tinctures and liqueurs were made from only a handful of edible flowers. They were and still are willingly consumed, as well as being used for medicinal and cosmetic purposes. An example of such products is rose liqueur [12]. Tinctures and liqueurs from edible flowers are produced in small craft factories and at home, and very rarely in industrial conditions. Traditional tinctures usually contain about $40-45 \%(v / v)$ alcohol. Currently, tinctures are also produced industrially, but they are definitely different from traditional tinctures. The process of producing commercial tinctures has little to do with traditional methods. They are obtained by mixing different extracts and have a lower alcohol content [6].

In contrast, liqueurs are distinguished from tinctures by a significantly higher inverted sugar content. They may also contain less alcohol. Insofar as tinctures are not regulated, liqueurs are defined in Regulation (EU) 2019/787 of the European Parliament and of the Council of 17 April 2019 [13]. In the EU, alcoholic beverages are excluded from Regulation $1169 / 2011$ on the provision of food information to consumers (FIC), which requires food labels to include information on ingredients, including nutrients [14].

The aim of this paper is to present selected tinctures of edible flowers from home and craft production, their phenol content, their antioxidant properties and colour in the CIE $\mathrm{L}^{*} \mathrm{a}^{*} \mathrm{~b}^{*}$ system. The article does not focus on spirits intended for medicinal purposes as tinctures. The procurement of medicinal tinctures and the requirements imposed on them are governed by separate regulations, similar to all other therapeutic agents.

The research aims to provide information on new alcohol products. Tinctures of edible flowers are made at home, but they are becoming of interest to craft production. Thanks to this research, manufactures can decide to start producing tinctures of edible flowers.

\section{Characteristics of Edible Flowers Used for Tinctures}

Edible flowers are defined as harmless and nontoxic flowers with health benefits that can form part of the human diet. The most frequently mentioned edible flowers are rose flowers and petals (Rosa spp.), elderberry flowers (Sambucus nigra L.), flowers and petals of Calendula off. L. and flowers or more often petals of cornflower, Centaurea cyanus L.

The genus Rosa L. includes over 120 species occurring mainly in the temperate and subtropical zones of the Northern Hemisphere. Rosa canina L. occupies a special place among the wild species. The flowers and petals of R. canina L. are mainly used for the production of oil and rose water $[15,16]$ and are used in medicine, aromatherapy, and the food cosmetic industries. Studies by Pires et al. [17] showed that rose petals of $R$. damascena, $R$. gallica and R. canina contain simple sugars, organic acids, fatty acids and tocopherols. Cendrowski et al. [18] suggest that due to the high content of bioactive compounds, especially polyphenols, including anthocyanins, flavonols and ellagitannins, Rosa rugosa petals may be a valuable raw material for the production of health-promoting preparations. Research by Nowak et al. [19] showed that Rosa rugosa petals exhibit cytotoxic, antioxidant and antibacterial properties. Until now, mainly R. canina L. fruits, but not flowers, have been used for the production of tinctures [20].

An edible flower known since the earliest times is the elderberry flower Sambucus nigra L. The flowers of this plant contain flavonoids (kaempferol, quercetin, naringenin), phenolic acids (of which chlorogenic acid is the most important), and vitamins (mainly vitamins of the B group and vitamin C). The total content of polyphenolic compounds can even be over $1000 \mathrm{mg} / 100 \mathrm{~g}$ fresh weight and can sometimes be higher than in the fruit. The contents depend on the conditions in which the drying of the plant material was performed, the extraction method, and the solvent used, which in turn affects the antioxidant properties of the obtained extracts [21,22]. Research shows that the temperature of the infusing water is of great importance for the medicinal value of elderberry flowers. Elderberry flowers were used medicinally as a diaphoretic, for colds and flu, as an analgesic for joint pain, and as a diuretic, antiviral and antibacterial agent. Elderberry flower extracts also show antidiabetic activity by activating glucose metabolism, and are used in cardiovascular 
diseases [23,24]. The mechanisms of action and the clinical aspect of the action of natural compounds are widely discussed by Lichota et al. [25]. Various forms of elderberry flower are increasingly used in food as colorants for juices, drinks, jams, confectionery, teas and in the pharmaceutical industry [22].

Calendula officinalis L., also called marigold, is a medicinal and ornamental plant. Marigold has been used in medicine since ancient times. Today, Calendula off. preparations are used mainly in dermatology for the treatment of skin diseases, burns, and also for patients after radiotherapy. Preparations with marigold extract can also be used as protection against sunlight, but their SPF is not high and amounts to 14.8 [26]. Efstratiou et al. [27] showed that marigold extracts possess antibacterial properties. The healing effect of Calendula off. is associated with the presence of calendulosides belonging to triterpene saponins, and flavonoids (mainly quercetin derivatives), phytosterols, carotenoids and coumarin [28,29]. Marigold owes its colour, ranging from yellow through to orange to dark red, to carotenoids, including $\alpha$ - and $\beta$-carotene, flavoxanthin, luteoxanthin, lycopene, and lutein and its derivatives isolated mainly from marigold flowers [30]. Toxicological studies also excluded the risks associated with the use of Calendula off. and recognized that the extracts and oils obtained from marigold are safe and can be used in cosmetics [31]. In order to ensure the highest quality of preparations containing marigold extracts, modern methods of flower drying, sonication-assisted extraction and supercritical extraction are used, as well as microencapsulation of bioactive compounds for use in cosmetics and pharmaceuticals [32].

Of the many representatives of the genus Centaurea L., Centaurea cyanus L. has gained the most importance. This common weed has been used in medicine for centuries and serves as an anti-inflammatory and diuretic agent. Its beneficial anti-inflammatory effects are used, among others, in ophthalmology. The medicinal raw material is its flowers, specifically its petals, which should be dried very carefully and stored in airtight vessels. It owes its colour to cyanidin glycosides, which include cyanine and pelargonidin. The colour pigment is essentially a metalloanthocyanin complex formed by anthocyanin, flavone and $\mathrm{Fe}^{3+}$ and $\mathrm{Mg}^{2+}$ ions [33]. Organic acids with a predominance of succinic acid were identified in C. cyanus petals. The petals also contain tocopherols, primarily in the $\alpha$ form. Cornflower extracts also contain phenolic acids, most of which are chlorogenic acid, which is responsible for its antioxidant properties. Flavonoid compounds are represented by apigenin and quercetin. The anthocyanin profile is formed by four cyanidin derivatives, and thanks to this, C. cyanus is used as a natural dye in the food, pharmaceutical and cosmetic industries [34]. The research carried out by this team shows that not only the petals of $C$. cyanus can be used, but also the flower receptacle, which has so far been rejected. Dried cornflower petals are frequent components of herbal teas [35]. Blue C. cyanus L. flowers are also of great interest as a potential source of natural colouring agents, as well as in food preparation and for decorating dishes [36].

\section{Materials and Methods}

\subsection{Materials}

Tinctures from rose petals, elderberry flowers, marigold and cornflower were obtained from a home-based manufacturer who produced them for their own needs. The tinctures from craft production were a rosehip tincture, produced by Manufaktura Piwniczka Smaku Kamil Maciantowicz \& Themelsle in Ruda Śląska, and an elderberry tincture Ciechocińska tincture of elderberry flowers distributed by the company IZI from Aleksandrów Kujawski and produced by the manufacturer of alcoholic beverages, Copernicus in Nieszawa.

All raw flower materials in fresh or dried form came from the local Polish market. For the production of tinctures of rosehip, elderberry flowers and cornflower, fresh flowers collected from natural sources in June-July 2018 were used, while for the production of the marigold tincture, fresh and dried petals from a noncertified flower garden cultivating edible flowers for consumption purposes from June 2018 were used. Two-stage, static, mixed maceration was carried out, using an aqueous spirit solution in the first phase, 
and sugar syrup in the following maceration. The flowers were placed in glass jars and had pure alcohol at a concentration of $40 \%$ poured onto them and were macerated at room temperature $\left(20 \pm 2{ }^{\circ} \mathrm{C}\right)$ for a period of $4-8$ weeks. After the maceration period, the tinctures were poured into clean glass vessels and the flowers were mixed with sugar syrup and macerated again for a period of 2-4 weeks. After this, the second macerate was drained and combined with the first macerate without sugar. In the case of some of the commercially available craft tinctures, protected recipes precluded us from obtaining additional details on the production methods.

The following reagents were used in the study: gallic acid (Sigma-Aldrich, Poznan, Poland), methanol (HPLC grade, Avantor Performance Materials Poland S.A., Gliwice, Poland), 1,1-diphenyl-2-picrylhydrazyl (DPPH) (Sigma-Aldrich, Poznań, Poland), FolinCiocaulteu reagent (Chempur, Piekary Śląskie, Poland), $\mathrm{Na}_{2} \mathrm{CO}_{3}$ (Avantor Performance Materials Poland S.A., Gliwice, Poland). All reagents were of analytical grade.

\subsection{Determination of Total Polyphenols}

Total phenol content in the tinctures of edible flowers was determined using the Folin-Ciocalteu reagent. Total phenolic content was measured using the Folin-Ciocalteu colorimetric method according to Singleton and Rossi [37] and the ISO 14502-1 standard. Two and half $\mathrm{mL}$ of Folin-Ciocalteu reagent, or appropriately diluted gallic acid standard methanolic solution, or water as a blank, were added to $0.5 \mathrm{~mL}$ tinctures of edible flowers (previously diluted 10-fold) and mixed. After $15 \mathrm{~min}, 2.0 \mathrm{~mL}$ of $20 \% \mathrm{Na}_{2} \mathrm{CO}_{3}$ was added, mixed and samples were left for $60 \mathrm{~min}$ at room temperature in the dark. Absorbance was read at $760 \mathrm{~nm}$ [UNICAM UV/Vis Spectrometer UV2] and the results were expressed as $\mathrm{mM}$ Gallic Acid Equivalents (GAE) per $100 \mathrm{~mL}$ of tinctures of edible flowers using the linear regression value obtained from the gallic acid calibration curve $(y=0.5069 x-0.4165$; $R^{2}=0.9886$ ). All the determinations were performed in four repetitions.

\subsection{Determination of the Antioxidant Potential}

The total antioxidant potential of samples was determined by using the procedure described by Brand-Williams, Cuvelier and Berset [38]. One $\mathrm{mL}$ of the edible flower tinctures were added to $2 \mathrm{~mL}$ of DPPH $(7.78 \mathrm{mg} / 100 \mathrm{~mL}$ methanol) followed by vigorous stirring. The DPPH solution was then allowed to stand for $15 \mathrm{~min}$ before absorbance was measured at $517 \mathrm{~nm}$ using a Varian Spectraa 250plus spectrophotometer. Spectrophotometric measurements were made using methanol as blank. The reaction was allowed to take place in the dark at room temperature until a plateau was reached. The ability of extracts to scavenge DPPH free radicals was calculated according to the following equation:

$$
\mathrm{AA}[\%]=\frac{\mathrm{Abs}_{\mathrm{contr}}-\mathrm{Abs}_{\text {sample }}}{\mathrm{Abs}_{\mathrm{contr}}} \times 100,
$$

where: $\mathrm{Abs}_{\text {contr }}$ is the absorbance of control incubation and $\mathrm{Abs}_{\text {sample }}$ is the absorbance of the tested sample. All tests were performed in four repetitions.

\subsection{Determination of Colour Parameters}

The tincture colour, as a parameter that can be used to estimate the quality of the tinctures [12], was determined by the international CIE L*a*b* D65 system using a Konica Minolta CR-400 colorimeter for a standard $10^{\circ}$ observer and at light source D65 [CIE DS. 014-4.3/E:2007] [39]. The measurement was made in an optical cell with an optical path length of $10 \mathrm{~mm}$. The $\mathrm{L}^{*}$ component, describing brightness, and $\mathrm{a}^{*}$ and $\mathrm{b}^{*}$ components, describing the proportion of green $(-)$ and red $(+)$, as well as blue $(-)$ and yellow $(+)$, respectively, were determined. The determination was made in four replications for each tincture. 


\subsection{Statistical Analysis}

Statistical analysis of the results included the calculation of basic measures such as the mean value. Significances of the parameters for different brands of tinctures were determined using STATISTICA ${ }^{\mathrm{TM}} 12$. The Kruskal-Wallis test was performed for testing significant group differences, followed by the post hoc Mann-Whitney U test, to determine which groups differed significantly. The level of significance was set as $p=0.05$.

\section{Results and Discussion}

Tinctures produced at home and by craft manufacturers (in the cases of tinctures of rose petals and elderberry flowers) were analysed for total polyphenol content, DPPH antioxidant activity and colour, by the CIE L*a* $\mathrm{b}^{*}$ system. The characteristics of tinctures subject to analysis are presented in Table 1 . To aid in the discussion of the colour parameters in the CIE L*a*b* system, in Figure 1 we present the photographic documentation of the actual colour of tinctures.

Table 1. Characteristics of tinctures and liqueurs from edible flowers produced at home and in craft factories.

\begin{tabular}{|c|c|c|c|c|c|}
\hline Tincture Name & Plant Organ & $\begin{array}{c}\text { Tincture } \\
\text { Composition }\end{array}$ & $\begin{array}{l}\text { Ethanol } \\
\text { Contents }\end{array}$ & Sugar Contents & $\begin{array}{c}\text { Flower Raw } \\
\text { Material } \\
(\mathrm{g} / 100 \mathrm{~mL})\end{array}$ \\
\hline $\begin{array}{l}\text { Home tincture from } \\
\text { wild rose flowers } \\
\text { Rosa canina L. }\end{array}$ & Rose petals & $\begin{array}{l}\text { rose petals, alcohol } \\
40 \% \text {, sugar, water }\end{array}$ & $27.5 \%$ & $200 \mathrm{~g} / \mathrm{L}$ & 1.75 \\
\hline $\begin{array}{l}\text { Craft tincture from } \\
\text { wild rose flowers } \\
\text { R. canina } L .\end{array}$ & $\begin{array}{l}\text { No information on } \\
\text { the label }\end{array}$ & $\begin{array}{l}\text { No information- } \\
\text { protected } \\
\text { formula }\end{array}$ & $30 \%$ & $\begin{array}{l}\text { No information- } \\
\text { protected } \\
\text { formula }\end{array}$ & $\begin{array}{c}\text { No information- } \\
\text { protected } \\
\text { formula }\end{array}$ \\
\hline $\begin{array}{l}\text { Home tincture from } \\
\text { elderberry flowers } \\
\text { Sambucus niger L. }\end{array}$ & Elderberry flowers & $\begin{array}{c}\text { elderberry flowers, } \\
\text { alcohol } 40 \% \text {, lemon } \\
\text { juice, }\end{array}$ & $40 \%$ & None & 18.6 \\
\hline $\begin{array}{l}\text { Home tincture from } \\
\text { elderberry flowers } \\
\text { S. niger L. }\end{array}$ & Elderberry flowers & $\begin{array}{l}\text { elderberry flowers, } \\
\text { alcohol } 40 \% \text {, lemon } \\
\text { juice, sugar, water }\end{array}$ & $28 \%$ & $350 \mathrm{~g} / \mathrm{L}$ & 9.3 \\
\hline $\begin{array}{c}\text { Craft tincture from } \\
\text { elderberry flowers } \\
\text { S. niger L. }\end{array}$ & No information & $\begin{array}{l}\text { No information- } \\
\text { protected } \\
\text { formula }\end{array}$ & $32 \%$ & $\begin{array}{l}\text { No information- } \\
\text { protected } \\
\text { formula }\end{array}$ & $\begin{array}{c}\text { No information- } \\
\text { protected } \\
\text { formula }\end{array}$ \\
\hline $\begin{array}{l}\text { Home tincture from } \\
\text { dried marigold } \\
\text { flowers } \\
\text { Calendula off. } L .\end{array}$ & $\begin{array}{l}\text { Dried marigold } \\
\text { flowers }\end{array}$ & $\begin{array}{l}\text { marigold flowers, } \\
\text { alcohol } 40 \%\end{array}$ & $40 \%$ & None & 10 \\
\hline $\begin{array}{l}\text { Home tincture from } \\
\text { dried marigold } \\
\text { flowers } \\
\text { Calendula off. } L \text {. with } \\
\text { orange juice }\end{array}$ & $\begin{array}{l}\text { Dried marigold } \\
\text { flowers }\end{array}$ & $\begin{array}{c}\text { marigold flowers, } \\
\text { alcohol } 40 \%, \\
\text { orange juice, }\end{array}$ & $38 \%$ & None & 3.33 \\
\hline $\begin{array}{l}\text { Home tincture from } \\
\text { fresh marigold flowers } \\
\text { Calendula off. } L \text {. }\end{array}$ & $\begin{array}{l}\text { Fresh marigold } \\
\text { flowers }\end{array}$ & $\begin{array}{l}\text { marigold flowers, } \\
\text { alcohol } 40 \%\end{array}$ & $38 \%$ & None & 10 \\
\hline $\begin{array}{l}\text { Home tincture from } \\
\text { cornflower flowers } \\
\text { Centaurea cyanus L. }\end{array}$ & $\begin{array}{l}\text { Dried cornflower } \\
\text { petals }\end{array}$ & $\begin{array}{l}\text { cornflower petals, } \\
\text { alcohol } 95 \% \text {, water }\end{array}$ & $38 \%$ & None & 2.96 \\
\hline
\end{tabular}




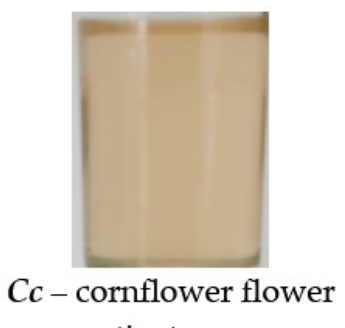
tincture

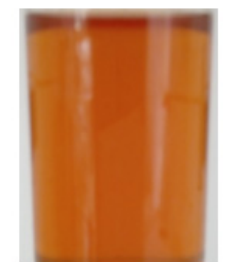

Sn_1-home-made tincture of elderberry flowers

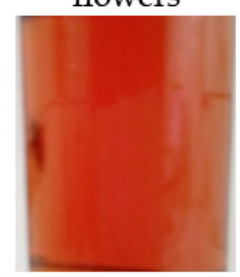

Co_1-home-made tincture of dried marigold flowers

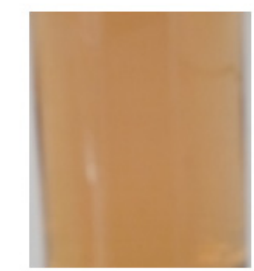

Rc_1-home-made tincture of wild rose flowers

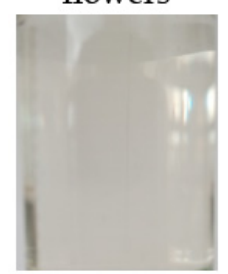

Sn_2-craft tincture of elderberry flowers

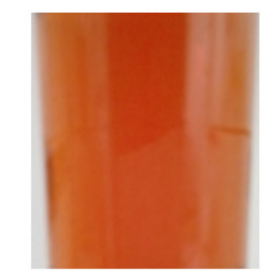

Co_2 - home-made tincture of dried marigold flowers with orange juice

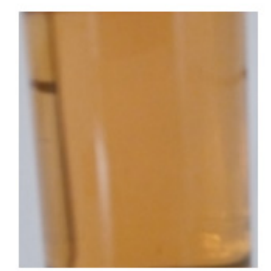

$R c \_2$ - craft tincture of wild rose flowers

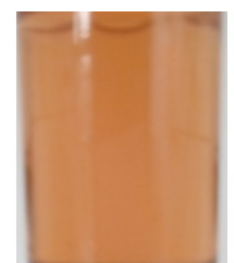

Sn_3-home-made tincture of elderberry flowers with added sugar

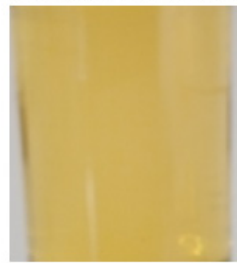

Co_3 - home-made

tincture of fresh marigold flowers

Figure 1. Photographs of the studied home- and craft-manufactured tinctures.

Table 2 presents the results for tinctures produced at home and in the manufactories. Due to the fact that the produced tinctures have various plant origins and are thus very different in terms of their nutritional properties and action, we decided to discuss them separately. First, tinctures of wild rose flowers, then elderberry flowers (more exactly elderberry canopies) and finally marigold flowers and cornflower flowers are discussed. The literature on preparations of edible flowers, including tinctures, is modest, which is why in the discussion we refer the results of research on edible flowers. This section may be divided by subheadings. It should provide a concise and precise description of the experimental results, their interpretation, as well as the experimental conclusions that can be drawn.

\subsection{Tinctures of Wild Rose Flowers (Rosa canina L.)}

Rose petals were most often used for making teas and preserves. In this article, we present the antioxidant properties and colour of home tinctures from Rosa canina L. rose petals. The total polyphenol content in tinctures varied depending on the method of production. The home tincture of rose flowers contained statistically less polyphenols than the craft tincture (Table 2). Unfortunately, in the literature there are no research results presenting the content of polyphenols in tinctures of edible flowers. In contrast, studies on polyphenol content in rose flowers by Chen et al. [40] showed that the content was between $86.63 \pm 0.57$ and $97.05 \pm 0.66 \mathrm{mg} \mathrm{GAE} / \mathrm{g}$. Other studies showed general polyphenol content in Rosa rugosa Thunb. rose flowers in the range of $25.79 \pm 0.20$ to $57.82 \pm 0.21 \mathrm{mg} \mathrm{GAE} / \mathrm{g}$ [4] In turn, Li et al. [41] determined in rose flowers a polyphenol content of $35.84 \pm 1.67 \mathrm{mg}$ $\mathrm{GAE} / \mathrm{g}$. The content of polyphenolic compounds in rose flowers, according to the authors, results from different varieties of roses, where a different content is found in Rosa canina L. 
and in Rosa rugosa Thunb. In addition, Chen et al. [42] drew attention to the fact that the colour of flowers affects the content of polyphenols. Purple Rosa rugosa Thunb. contained twice as much mg GAE/g as pink Rosa rugosa Thunb. The total polyphenol content in the craft tincture was three times higher (Table 2). However, it cannot be clearly stated how the method of preparation of the tincture affected its composition, because the production process is protected by the manufacturers. We can only assume that the tincture was obtained by adding rose extract to alcohol, however the form of this extract and the amount of this addition is unknown.

Table 2. Results of total polyphenol content (TP) and DPPH antioxidant activity, as well as tincture colour in the CIE L*a*b* system.

\begin{tabular}{|c|c|c|c|c|c|c|}
\hline & $\begin{array}{c}\text { TP } \\
\text { (mg GAE/ } \\
100 \mathrm{~mL})\end{array}$ & $\begin{array}{c}\text { TP } \\
\text { (mg GAE/g } \\
\text { Flowers) }\end{array}$ & $\mathbf{A A}_{\mathrm{DPPH}}[\%]$ & $\mathbf{L}^{*}$ & $a^{*}$ & $b^{*}$ \\
\hline & \multicolumn{6}{|c|}{ Tinctures of wild rose flowers Rosa canina $\mathrm{L}$. } \\
\hline Home & $15.72 \pm 0.16^{\mathrm{a}, \mathrm{D}}$ & $8.98 \pm 0.09$ & $69.77 \pm 10.16^{\mathrm{a}, \mathrm{A}, \mathrm{B}}$ & $21.18 \pm 0.01^{\mathrm{a}, \mathrm{B}}$ & $0.59 \pm 0.08^{a, D}$ & $4.29 \pm 0.05^{\mathrm{a}, \mathrm{B}}$ \\
\hline Craft & $46.78 \pm 0.75^{\mathrm{b}, \mathrm{G}}$ & no data & $81.87 \pm 7.71^{\mathrm{a}, \mathrm{A}}$ & $21.00 \pm 0.33^{\mathrm{a}, \mathrm{B}}$ & $1.66 \pm 0.24^{\mathrm{b}, \mathrm{B}}$ & $4.25 \pm 0.46^{\mathrm{a}, \mathrm{B}}$ \\
\hline \multirow{3}{*}{$\mathrm{U} M-\mathrm{W}^{1}$ statistics } & $z=-2.16$ & & $\mathrm{z}=-1.01$ & $z=0.14$ & $z=-2.16$ & $\mathrm{z}=0.14$ \\
\hline & $p=0.03 *$ & & $p=0.31$ & $p=0.88$ & $p=0.03 *$ & $p=0.88$ \\
\hline & \multicolumn{6}{|c|}{ Tinctures of elderberry flowers Sambucus niger L. } \\
\hline Home & $27.19 \pm 0.24^{\mathrm{c}, \mathrm{B}}$ & $1.46 \pm 0.01$ & $72.60 \pm 9.46^{\mathrm{a}, \mathrm{A}, \mathrm{B}}$ & $21.73 \pm 0.01^{\mathrm{a}, \mathrm{D}}$ & $1.32 \pm 0.05^{c, C}$ & $3.75 \pm 0.02^{b, E}$ \\
\hline Craft & $13.59 \pm 0.14^{\mathrm{a}, \mathrm{C}}$ & no data & $87.83 \pm 4.61^{\mathrm{b}, \mathrm{A}}$ & $26.16 \pm 0.02^{c, F}$ & $-0.45 \pm 0.02^{\mathrm{a}, \mathrm{A}}$ & $1.55 \pm 0.01^{\mathrm{a}, \mathrm{C}}$ \\
\hline $\begin{array}{l}\text { Home with } \\
\text { added sugar }\end{array}$ & $17.23 \pm 0.56^{\mathrm{b}, \mathrm{E}}$ & $1.85 \pm 0.06$ & $\begin{array}{c}81.25 \pm 6.78 \\
\mathrm{a}, \mathrm{b}, \mathrm{A}, \mathrm{B}\end{array}$ & $23.98 \pm 0.01^{b, C}$ & $0.33 \pm 0.04^{\mathrm{b}, \mathrm{D}}$ & $5.25 \pm 0.04^{\mathrm{c}, \mathrm{F}}$ \\
\hline \multirow[t]{3}{*}{$\mathrm{K}-\mathrm{W}^{2}$ statistics } & $\begin{array}{c}\mathrm{z}=9.85 \\
p=0.007 *\end{array}$ & & $\begin{array}{l}\mathrm{z}=5.54 \\
n=0.06\end{array}$ & $\begin{array}{c}\mathrm{z}=9.91 \\
n=0.007\end{array}$ & $\begin{array}{c}\mathrm{z}=9.91 \\
n=0.007 *\end{array}$ & $z=10.20$ \\
\hline & \multirow{2}{*}{\multicolumn{6}{|c|}{ Tinctures of marigold flowers Calendula off. L. }} \\
\hline & & & & & & \\
\hline $\begin{array}{l}\text { Home craft from } \\
\text { dried flowers }\end{array}$ & $27.08 \pm 0.33^{\mathrm{c}, \mathrm{B}}$ & $2.71 \pm 0.03$ & $41.23 \pm 19.18^{a, C}$ & $20.00 \pm 0.01^{\mathrm{a}, \mathrm{A}}$ & $1.65 \pm 0.02^{c, B}$ & $2.65 \pm 0.01^{\mathrm{a}, \mathrm{A}}$ \\
\hline $\begin{array}{l}\text { Home craft from } \\
\text { dried flowers } \\
\text { with orange juice }\end{array}$ & $25.89 \pm 0.22^{b, F}$ & $7.77 \pm 0.06$ & $56.81 \pm 15.48^{\mathrm{a}, \mathrm{B}, \mathrm{C}}$ & $20.03 \pm 0.01^{\mathrm{a}, \mathrm{A}}$ & $1.51 \pm 0.06^{\mathrm{b}, \mathrm{B}, \mathrm{C}}$ & $2.88 \pm 0.05^{\mathrm{b}, \mathrm{A}}$ \\
\hline $\begin{array}{l}\text { Home craft from } \\
\text { fresh flowers }\end{array}$ & $10.72 \pm 0.05^{\mathrm{a}, \mathrm{A}}$ & $1.07 \pm 0.01$ & $40.85 \pm 6.91^{\mathrm{a}, \mathrm{C}}$ & $22.88 \pm 0.02^{\mathrm{b}, \mathrm{E}}$ & $-0.23 \pm 0.03^{\mathrm{a}, \mathrm{A}}$ & $7.15 \pm 0.02^{c, G}$ \\
\hline \multirow[t]{2}{*}{$\mathrm{K}-\mathrm{W}^{2}$ statistics } & $\begin{array}{c}\mathrm{z}=9.85 \\
p=0.007 *\end{array}$ & & $\begin{array}{l}\mathrm{z}=1.85 \\
p=0.40\end{array}$ & $\begin{array}{c}\mathbf{z}=9.91 \\
p=0.007 *\end{array}$ & $\begin{array}{c}\mathrm{z}=9.85 \\
p=0.007 *\end{array}$ & $\begin{array}{c}\mathrm{z}=9.88 \\
p=0.007\end{array}$ * \\
\hline & \multicolumn{6}{|c|}{ Tinctures of cornflower flowers Centaurea cyanus L. } \\
\hline \multirow[t]{3}{*}{$\begin{array}{l}\text { Home craft of } \\
\text { dried petals }\end{array}$} & $9.93 \pm 0.45^{\mathrm{A}}$ & $3.36 \pm 0.15$ & $9.49 \pm 2.20^{\mathrm{D}}$ & $23.73 \pm 0.01^{C}$ & $-0.26 \pm 0.09^{\mathrm{A}}$ & $3.34 \pm 0.02^{\mathrm{D}}$ \\
\hline & \multicolumn{6}{|c|}{ Kruskal-Wallis statistics for all products } \\
\hline & $\begin{array}{c}z=34.32 \\
p=0.000 *\end{array}$ & & $\begin{array}{c}z=29.26 \\
p=0.0003 *\end{array}$ & $\begin{array}{c}z=34.32 \\
p=0.000 *\end{array}$ & $\begin{array}{c}\mathrm{z}=34.35 \\
p=0.0001 *\end{array}$ & $\begin{array}{c}\mathrm{z}=34.98 \\
p=0.000 *\end{array}$ \\
\hline
\end{tabular}

${ }^{1} U$-W-Mann-Whitney U statistics; ${ }^{2} \mathrm{~K}-\mathrm{W}$-Kruskal-Wallis statistics; $z$ Mann-Whitney U test statistic or Kruskal-Wallis test statistic value, respectively, $p$ probability value for tested hypotheses, ${ }^{*}$ statistically significant values at $p=0.05$. a-c letters-average values marked with the same letters do not differ statistically significantly within the group of tinctures from the same raw material; A-G letters-average values marked with the same letters do not differ statistically significantly within all tested products.

The difference in the DPPH scavenging ability of home and manufactured tinctures of $R$. canina was not statistically significant (Table 2). Previous studies on the ability to scavenge DPPH radicals by rose flower extracts showed that it depends on the plant variety, the type of extract (aqueous, methanol or using another solvent, e.g., acetone) and the extraction time [40-42]. There is apparent discrepancy between the total polyphenols content and DPPH scavenging ability differences for home and craft tinctures, however, due to the lack of access to the exact details of the craft manufacturing process, it is at present difficult to hypothesize about the origin of this discrepancy at the present stage of investigations.

Comparing the colour of tinctures of wild rose flowers, we note that the $\mathrm{L}^{*}$ parameter meaning brightness and the $b^{*}$ parameter representing yellow saturation, are almost identical (Table 2), while a difference was found in the value of the $a^{*}$ parameter, which 
reflects the share of red in the tinctures. It is higher in the craft tincture, implicating a more intense red colour. In the study of Schmitzer et al. [12] and Sokół-Łętowska et al. [43] it was noted that the colour of traditional fruit liqueur is influenced by plant varieties, flower drying conditions, and sugar content. From darker fruit and flower buds we obtain tinctures and liqueurs which contain more substances, such as anthocyanins, reacting with the Folin-Ciocalteu reagent.

\subsection{Tinctures of Elderberry Flowers (Sambucus niger L.)}

Black elderberry Sambucus niger L. is one of the wild plants that has been used as an edible plant and medicinal raw material for centuries [22]. Healing properties, however, were studied mainly for Sambucus niger L. fruits. In the literature, we find only one publication about elderberry liqueurs [6]. That is why our goal was to present the antioxidant properties of elderberry tinctures.

Tinctures of elderberry flowers Sambucus nigra L. are characterized by a difference in content of substances reacting with the Folin-Ciocalteu reagent betweem the tincture from the manufacture $(13.59 \pm 0.14 \mathrm{mg} \mathrm{GAE} / 100 \mathrm{~mL})$ and the sweetened tincture produced in home conditions $(17.23 \pm 0.56 \mathrm{mg} \mathrm{GAE} / 100 \mathrm{~mL})$. The home tincture of elderberry flowers without added sugar contained more polyphenolic substances $(27.19 \pm 0.24 \mathrm{mg}$ GAE/100 mL), resulting most probably from the greater content of the raw flower material than in the sweetened home tincture. All differences were statistically significant (Table 2).

Polak and Bartoszek [6] studied the elderberry tincture produced in the "Krakowski Kredens" industrial manufacture according to a traditional recipe and found that it contained $3649 \pm 64 \mathrm{~g} \mathrm{GA} / \mathrm{L}$. Studies on the content of polyphenolic substances in elderberry fruit Sambucus nigra L. show that they contain 371-432 mg GAE/100 g dry matter [44]. Młynarczyk et al. [22] determined in the fruits and flowers of elderberry Sambucus nigra L. a polyphenol content of 364-582 mg GAE/100 g fresh fruit weight and 1021.7 mg GAE/100 g fresh flower weight, respectively.

The craft tincture and home tincture of elderberry flowers with added sugar were characterized by a similar scavenging capacity of DPPH radicals, at $87.83 \pm 4.61$ and $81.25 \pm 6.78$, respectively. The home tincture, in turn, inhibited DPPH radicals at $72.60 \pm 9.46$. Similarly to the content of TPC, differences between antioxidant activity of elderberry tincture were statistically significant (Table 2). Higher DPPH scavenging ability of the craft tincture despite lower TP content might result from the presence of unspecified compounds which were not analysed in the current investigation, however, due to the protected composition of the product, it is at present difficult to hypothesize more about the actual reason for this observation. Dawidowicz et al. [45] studied the antioxidant properties of alcohol extracts from leaves, fruits and flowers of Sambucus nigra L. depending on the extraction temperature, and found that at $20^{\circ} \mathrm{C}$, the ability to sweep DPPH radicals in flower extracts was $91.95( \pm 0.12)$ and at $100{ }^{\circ} \mathrm{C}$ it was $94.15( \pm 0.32)$. In addition, the authors of the study showed that the ability to scavenge DPPH free radicals by extracts of Sambucus nigra L. leaves increased with an increasing extraction temperature. Ferreira et al. [46] showed that the antioxidant properties of Sambucus nigra L. are also influenced by other factors such as the harvest year, elderberry variety, climate, rainfall volume, and harvest time.

The value of the $L^{*}$ brightness parameter in the CIE $\mathrm{L}^{*} \mathrm{a}^{*} \mathrm{~b}^{*}$ system was slightly different for the Sambucus nigra L. flower extract, while the values of the $\mathrm{a}^{*}$ and $\mathrm{b}^{*}$ parameters, representing red and yellow saturation, respectively, were significantly different (Table 2). The largest share of red was found in the home tincture and the smallest in the craft tincture. However, the value of the $b^{*}$ parameter was the smallest for the tincture from the manufacturer and the largest for the homemade one, which indicates that the tincture with the addition of sugar has the largest proportion of yellow. Vujanović et al. [47] remarked that the colour of juices and extracts obtained from Sambucus nigra L. is influenced by the drying conditions of the raw material (traditional drying, freeze-drying or microwave drying), the solvents used, and the temperature of the process. It was noted that extraction with methanol and ethanol had a significant effect on the colour and resulted in greater 
pigment extraction. In our opinion, differences in the colour of the tinctures result from a different technology of obtaining them. The fact that the craft-manufactured tincture is devoid of the characteristic yellow-red tint common to other edible flower tinctures (cf. Figure 1), coupled with the evidently lower total polyphenol content hints at the possible absence of the important elderberry polyphenols (quercetin and kaempferol) that contribute to the colour of the tincture. The fact that despite this low polyphenol content, the craft-manufactured tincture still shows high DPPH scavenging ability (cf. Table 2) suggests the presence of unspecified additives showing antioxidant activity that may have been added to alter the final sensory properties of the product.

\subsection{Tinctures of Marigold Flowers (Calendula officinalis L.)}

Marigold Calendula officinalis L. is a plant that has been known since antiquity. It was used as a medicinal product for internal and external ailments of various skin diseases. Currently, it is also used as a food, and as a medicinal and cosmetic product [26,44]. The pharmacological activity of marigold is associated with the content of various secondary metabolites, such as essential oils, flavonoids, sterols, carotenoids, tannins, saponins, triterpene alcohols, polysaccharides, bitter substances, mucilage and resin $[27,28,45,46]$. Marigold flowers, due to their beautiful colour, are used to decorate and colour dishes.

The growing interest in edible flowers has resulted in marigold being used to make tinctures. According to the manufacturer of these home tinctures, this is a unique flower. Tinctures were obtained from dried and fresh flowers. Because of the bitter taste of the tincture of dried Calendula off. L., the producer used the addition of an orange juice.

Tinctures of marigold flowers obtained from dried flowers and from dried flowers with the addition of orange juice were characterized by a different content of substances reacting with the Folin-Ciocalteu reagent, which amounted, respectively to $27.08 \pm 0.33$ and $25.89 \pm 0.22 \mathrm{mg} \mathrm{GAE} / 100 \mathrm{~mL}$ (Table 2). The fresh flower tincture on the other hand contained more less than half of the polyphenolic compounds expressed as GAE. All differences were statistically significant (Table 2). It is instructive to compare the results for dried marigold flower tinctures with and without added orange juice when expressed in $\mathrm{mg} \mathrm{GAE} / \mathrm{g}$ raw material. The fact that the addition of orange juice would result in almost three times the GAE content than the alone flowers strongly suggests that most of the antioxidative power of the tincture with added juice comes directly from this addition, as orange juice is known for its strong antioxidative ability, most importantly due to the abundance of ascorbic acid in citrus juices.

No articles on marigold tinctures were found in the literature. The study by Ćetković et al. [48] shows that the content of polyphenolic compounds in marigold flowers depends on the variety. They found, in alcoholic extracts of dried marigold flowers Calendula arvensis L., the presence of polyphenolic compounds at the level of $14.49 \pm 0.38 \mathrm{mg} / \mathrm{g}$, and slightly more in the water extract, at $15.12 \pm 0.40 \mathrm{mg} / \mathrm{g}$. In turn, Calendula off. L. alcohol macerates contained polyphenols at $55.07 \pm 1.11 \mathrm{mg} / \mathrm{g}$, and in water extracts the level was $57.47 \pm 1.12 \mathrm{mg} / \mathrm{g}$. Butnariu and Coradini [49] stated that in the Calendula off. L. extract, the presence of compounds reactive with the Folin-Ciocalteu reagent was at the level of 120-150 mg GAE/100 mL.

Tinctures of marigold flowers in this work were also characterized by diverse antioxidant activity. The homemade tincture of dried flowers and the fresh flower tincture had similar capabilities for scavenging of DPPH radicals, at $41.23 \pm 19.18$ and $40.85 \pm$ $6.91 \%$, respectively (Table 2). In contrast, the tincture of dried marigold flowers with the addition of orange juice scavenged $56.81 \pm 15.48 \%$ of DPPH radicals. However, this difference was not statistically significant (Table 2). At this stage of research, it is difficult to explain the reasons for these differences. However, we can hypothesize that the higher TP content in the dried-vs. fresh-flowers home tinctures may result from the fact that dried flowers contain more polyphenols in the same mass due to the absence of water present in fresh flower material. Apparently contradictory results of DPPH scavenging ability may be explained by the presence of other substances reacting with DPPH in fresh flowers, 
which may decompose during the drying process. However, we do not know the exact drying conditions of the flowers, and they can be decisive for the content of biologically active ingredients.

Ćetković et al. [48] found higher antioxidant activity of Calendula off. than C. arvensis, while methanol extracts showed lower activity than aqueous extracts. The effect of the solvent on the antioxidant activity of marigold extracts has also been found by Ercetin et al. [50]. C. arvensis and C. officinalis flowers were extracted with n-hexane, dichloromethane, acetone, ethyl acetate, methanol and distilled water at room temperature. Acetone extracts were characterized by a higher capacity for scavenging DPPH radicals, and this activity was higher for $C$. arvensis.

The antioxidant activity of dried marigold flowers also depends on the drying method. Dorozko et al. [51] showed that the activity of Calendula off. flower extracts dried with hot air, microwave and lyophilization, differs, and that extracts of flowers dried using the microwave method were characterized by the greatest activity.

The colour of homemade Calendula off. tinctures measured with the $L^{*}$ parameter, which denotes brightness, is very similar for all tinctures and is in the range $20.00 \pm 0.01-22.88 \pm 0.02$ (Table 2). However, the values of the $b^{*}$ parameter are different, and it is negative for the craft tincture (Table 2). Statistically significant differences were also found in the value of the parameter $\mathrm{a}^{*}$, which reflects the share of red in the tinctures. It is three times higher in the home tincture of fresh Calendula off. flowers. In the petals of fresh flowers, Kishimoto et al. [52] found the presence of nineteen carotenoids in the form of carotenoids, lycopene and rubixanthin in yellow and orange calendula extracts, which are responsible for the colour of marigold extracts. Researchers believe marigold petals have a unique carotenoid composition that is reflected in their colour.

\subsection{The Cornflower Tincture (Centaurea cyanus L.)}

Cornflowers, Centaurea L., are very popular plants belonging to the Asteraceae family. The most popular representative of this family is the blue cornflower C. cyanus L. Cornflower, also called bluecup, despite being a weed is a very important medicinal and cosmetic raw material with anti-inflammatory properties. Dried cornflower petals are components of herbal teas [52]. Blue C. cyanus L. flowers are of great interest as a potential source of natural colouring agents, as well as in food preparation and for decorating dishes [53].

The growing interest in edible flowers has caused cornflower $C$. cyanus $\mathrm{L}$. to be used to make tinctures. Of all the homemade tinctures that are the subject of this study, the cornflower tincture of $C$. cyanus L. contains the lowest number of compounds that react with the Folin-Ciocalteu reagent (Table 2). The content of these compounds remains in the tincture of cornflower petals at the level of $9.93 \pm 0.45 \mathrm{mg} \mathrm{GAE} / 100 \mathrm{~mL}$ (Table 2). There is no research conducted so far on the content of polyphenolic compounds in tinctures of cornflower petals C. cyanus L. In the studies of Escher et al. [53] it was demonstrated that the total polyphenol content in cornflower petals was from $393 \pm 1$ to $485 \pm 8 \mathrm{mg} \mathrm{GAE} / 100 \mathrm{~g}$. In the aqueous extracts of cornflower, Różyło et al. [54] determined $43.48 \pm 1.33 \mathrm{C} \mathrm{mg}$ GAE/g total polyphenols.

The homemade tincture of cornflower petals also has a relatively low ability to scavenge DPPH radicals at the level of $9.49 \pm 2.20 \%$ compared to other tinctures tested in this study (Table 2). In the aforementioned studies, Escher et al. [53] found that the antioxidant activity of extracts by the DPPH radical method ranged from $51 \pm 1-63 \pm 1 \%$ inhibition. The colour of tinctures from cornflower petals measured with the $L^{*}$ parameter, which means brightness, is very similar for all tinctures and is $23.73 \pm 0.01$ (Table 2). The parameter $\mathrm{a}^{*}$ has a negative value of $-0.26 \pm 0.09$, which indicates the absence of red. However, the value of the $b^{*}$ parameter is $3.34 \pm 0.02$, indicating a moderate proportion of yellow (Table 2). In turn, Różyło et al. [54], determined the colour of dried cornflower petals in the CIE L*a* ${ }^{*}$ system and obtained the results of $32.5,4.1$, and -7.9 , respectively. Additionally, 
the study by Lockowandt et al. [34] shows that the colour of cornflower flowers is mainly shaped by anthocyanins, including four cyanidin derivatives.

Cluster analysis, carried out on the basis of antioxidant properties and colour parameters of the studied tinctures, allowed us to isolate groups of tinctures with similar profiles (Figure 2).

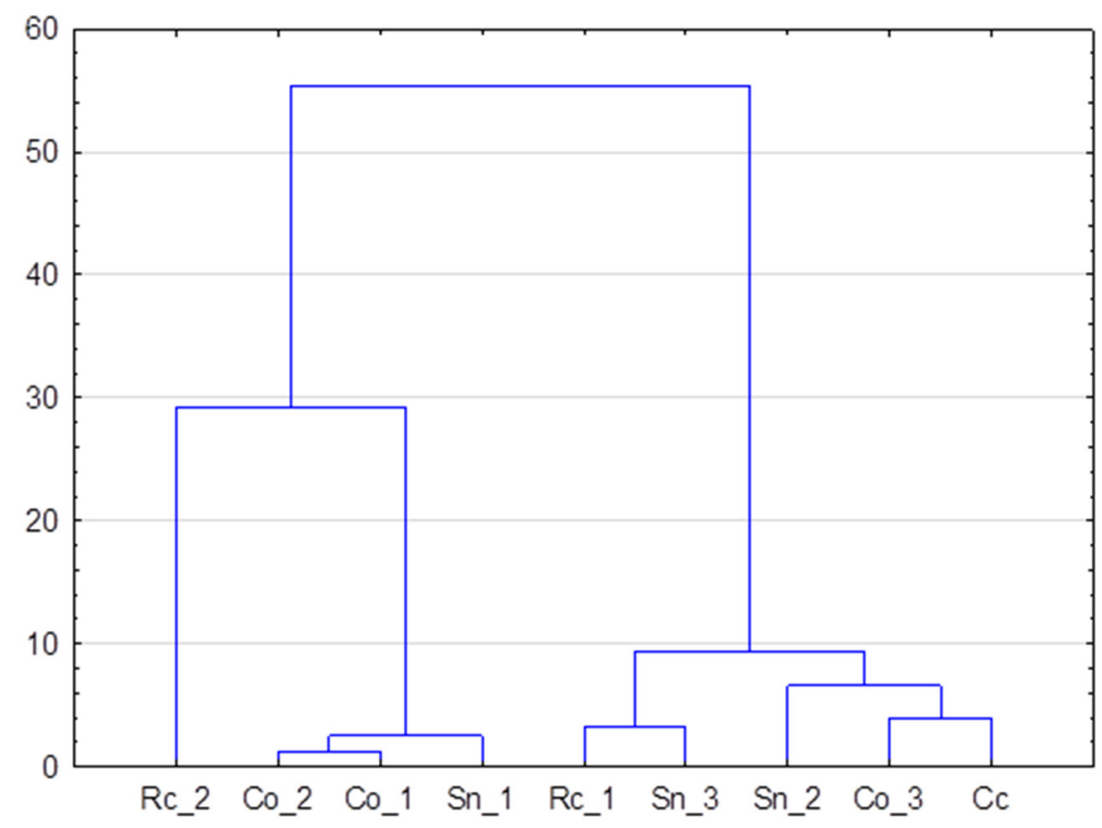

Figure 2. Analysis of the content of compounds reacting with the Folin-Ciocalteu reagent and the colour measured by the CIE $L^{*} a^{*} b^{*}$ method by dendrograms using the Ward method with Euclidean distances; Cc_cornflower flower tincture Centaurea cyanus L.; Sn_1-homemade tincture of elderberry flowers Sambucus niger L.; Sn_2-craft tincture of elderberry flowers Sambucus niger L.; Sn_3-homemade tincture of elderberry flowers Sambucus niger L. with added sugar; Co_1homemade tincture of dried marigold flowers Calendula off. L.; Co_2-homemade tincture of dried marigold flowers Calendula off. L. with orange juice; Co_3-homemade tincture of fresh marigold flowers Calendula off. L.; Rc_1-homemade tincture of wild rose flowers Rosa canina L.; Rc_2—craft tincture of wild rose flowers Rosa canina L.

As a result of this analysis, it was found that the tincture's classification to a given cluster is a differentiating factor. The obtained clusters denote tinctures that significantly differ in the values of the determined parameters. With the number of clusters selected for interpretation, the relative homogeneity of the clusters was observed, as well as the fact that they form at a similar binding distance. The larger differences in Euclidean distances allow the assumption that the clusters reflect differing groups of variables.

As the quality evaluation for each of the defined clusters, the average value of the grades included in its observed variables was adopted. Three main clusters were identified. The first is formed by two homemade tinctures: cornflower flower tincture Centaurea cyanus L. (Cc) and fresh marigold flowers tincture Calendula off. L. (Co_3) and one commercial tincture, the craft tincture of elderberry flowers Sambucus niger L. (Sn_2). Tinctures from this group were characterized by the lowest content of polyphenolic compounds-9.93, 10.72 and $13.59 \mathrm{mg} \mathrm{GAE} / 100 \mathrm{~mL}$, respectively. The vast majority of them were characterized by the least intense red colour (negative values of the parameter $\mathrm{a}^{*}$ ), and were the brightest off all tinctures (high values of the parameter $\mathrm{L}^{*}$ ). In addition, this group includes the homemade tincture made of fresh flowers ( $\left.\mathrm{Co}_{-} 3\right)$, characterized by the highest saturation of yellow (the highest value of parameter $b^{*}$ ). The differences in colour between these tinctures, designated as the $\Delta \mathrm{E}$ parameter, was 6.57 between $\mathrm{Co} \_3$ and Sn_2, indicating significant differences. However, between tinctures $C \mathrm{C}$ and $\mathrm{Sn} \_2(\Delta \mathrm{E}=3.03)$ and $\mathrm{Co} \_3$ and 
Cc $(\Delta \mathrm{E}=3.9)$, significant differences in colour were also observed in connection with the use of different production technologies.

The next dimension groups two homemade tinctures: homemade tincture of wild rose flowers Rosa canina L. (Rc_1) and homemade tincture of elderberry flowers Sambucus niger $\mathrm{L}$. with added sugar ( $\left.\mathrm{Sn} \_3\right)$. Tinctures not distinguished by any of the parameters were classified in this group. They were tinctures with average-in relation to tinctures from other clusters-antioxidant properties (average content of polyphenolic compounds in the range of 15.72-17.23 mg GAE/100 mL) and colour parameters. This group includes tinctures with the lowest saturation of red (low values of the parameter $\mathrm{a}^{*}$ ) and higher saturation of the yellow than tinctures grouped in the previous cluster (average values of the parameter $b^{*}$ range from 4.29 to 5.25). The difference in colour between these tinctures was not significant. The calculated value of $\Delta \mathrm{E}$ was 2.98 .

The third group is formed by three home tinctures: the homemade tincture of dried marigold flowers Calendula off. L. (Co_1), the homemade tincture of dried marigold flowers Calendula off. L. with orange juice (Co_2) and the homemade tincture of elderberry flowers Sambucus niger L. (Sn_1). Characteristic features of tinctures from this group are a high content of bioactive compounds (on average from 25.89 to $27.19 \mathrm{mg} \mathrm{GAE} / 100 \mathrm{~mL}$ ) and an average intensity of red (parameter $\mathrm{a}^{*}$ on average from 1.32 to 1.65 ) and yellow (parameter $\mathrm{b}^{*}$ on average from 2.65 to 3.75 ) colours. Despite the addition of orange juice, no significant difference in colour was found between $\mathrm{Co}_{-} 1$ and $\mathrm{Co} \_2$ tinctures $(\Delta \mathrm{E}=0.27)$. Slightly larger differences were noted between the tinctures $S n \_1$ and $C o \_1(\Delta E=2.08)$ and $S n \_1$ and Co_2 $(\Delta \mathrm{E}=1.92)$.

From the graph, we can also see that cutting off the graph at the standard binding distance (ca. 10) gives a single sample unrelated to the other tinctures. This sample is the industrial-scale produced tincture- the craft tincture of wild rose flowers, Rosa canina L. (Rc_2), which clearly differed from the other tinctures, with the highest content of polyphenolic compounds (on average $46.78 \pm 0.75 \mathrm{mg} \mathrm{GAE} / 100 \mathrm{~mL}$ ). In terms of colour parameters, the tincture was characterized by values similar to those described in the second cluster. The largest differences in the colour of this tincture were calculated in relation to another industrial tincture - the craft tincture of elderberry flowers Sambucus niger L. (Sn_2).

The presented classification allowed the identification of tincture groups with similar antioxidant profiles and colours. The suitability of individual colour parameters for identifying these tinctures in terms of production method has been demonstrated. Some similarities have been marked in terms of individual quality characteristics, but on their basis it cannot be unequivocally determined that home tinctures are characterized by attributes or intensities that are not found in commercial tinctures.

\section{Conclusions}

Edible flowers, in addition to preparing dishes and decorating them, are also used to make alcoholic tinctures. Tinctures are an important cultural heritage in the tradition of Eastern European countries, which in the opinion of many researchers have been ignored, and are now returning with the wave of increased interest in natural raw materials in medicine, food and nutrition, and a return to the use of ethnobotanical knowledge [55-57]. This paper presents tinctures of rose petals, elderberry flowers, marigold and cornflower flowers obtained at home, as well as rose and elderberry tinctures produced by craft manufactures. Tinctures were characterized by variable content of total phenolic compounds, antioxidant properties and colour. The determined parameters were influenced by the form of flowers (fresh or dried) and their quantity, as well as the addition of sugar. The CIE L $\mathrm{a}^{*} \mathrm{~b}^{*}$ colour parameters may possibly be used to detect the authenticity of flower tinctures, as evidenced by the great disparity between the colour of the homemade and commercial elderberry tincture.

Edible flower tinctures can be an interesting offer in the group of medium alcoholic beverages. Due to the original, vivid and expressive colours, they can be served as exquisite 
drinks accompanying coffee and desserts. In addition, research has shown that natural radical scavenging antioxidants may be beneficial. Moderate consumption (i.e., within the safety limits suggested by the relevant health authorities [58]) of alcoholic beverages rich in antioxidant compounds may have cardioprotective action and provide protection against cardiovascular risk factors, as shown in other studies for wine and herbal spirits [59]. Moreover, consumers increasingly often look for natural, original products with additional health-promoting properties [60]. Though the current research should be extended to a wider range of compounds with antioxidant activity, the present findings show that the proposition of tinctures based on edible flowers may be an interesting offer for such consumers.

Author Contributions: Conceptualization, M.Ś. and P.D.; methodology, M.Ś. and P.D.; software, P.D.; validation, M.Ś., P.D. and L.S.; formal analysis, L.S.; investigation, M.Ś.; resources, M.Ś., P.D. and L.S.; data curation, M.Ś., P.D. and L.S.; writing-original draft preparation, M.Ś.; writingreview and editing, M.Ś. and P.D.; visualization, P.D.; supervision, M.S.; project administration, M.Ś.; funding acquisition, M.Ś. and P.D. All authors have read and agreed to the published version of the manuscript.

Funding: This research was supported in part by Gdynia Maritime University, grant no. WZNJ/ 2021/PZ/04.

Institutional Review Board Statement: Not applicable for studies not involving humans or animals.

Informed Consent Statement: Not applicable for studies not involving humans.

Data Availability Statement: Data available from authors on request.

Conflicts of Interest: The author declares no conflict of interest.

\section{References}

1. Śliwińska, M.; Wiśniewska, P.; Dymerski, T.; Wardencki, W.; Namieśnik, J. The flavor of fruit spirits and fruit liqueurs: A review. Flavour Fragr. J. 2015, 30, 197-207. [CrossRef]

2. Sznitowska, M. Applied Pharmacy. Drug Form Technology; PZWL: Warsaw, Poland, 2017. (In Polish)

3. Crupi, M.L.; Costa, R.; Dugo, P.; Dugo, G.; Mondello, L. A comprehensive study on the chemical composition and aromatic characteristics of lemon liquor. Food Chem. 2007, 105, 771-783. [CrossRef]

4. Egea, T.; Signorini, M.A.; Bruschi, P.; Rivera, D.; Obón, C.; Alcaraz, F.; Palazón, J.A. Spirits and liqueurs in European traditional medicine: Their history and ethnobotany in Tuscany and Bologna (Italy). J. Ethnopharmacol. 2015, 175, 241-255. [CrossRef]

5. De Jesus Filho, M.; do Carmo, L.B.; Della Lucia, S.M.; Saraiva, S.H.; Costa, A.V.; Teixeira, L.J.Q. Banana liqueur: Optimization of the alcohol and sugar contents, sensory profile and analysis of volatile compounds. LWT 2018, 97, 31-38. [CrossRef]

6. Polak, J.; Bartoszek, M. The study of antioxidant capacity of varieties of nalewka, a traditional Polish fruit liqueur, using EPR, NMR and UV-vis spectroscopy. J. Food Compos. Anal. 2015, 40, 114-119. [CrossRef]

7. Stampar, F.; Solar, A.; Hudina, M.; Veberic, R.; Colaric, M. Traditional walnut liqueur-Cocktail of phenolics. Food Chem. 2006, 95, 627-631. [CrossRef]

8. Tuberoso, C.I.G.; Boban, M.; Bifulco, M.; Budimir, D.; Pirisi, F.M. Antioxidant capacity and vasodilatory properties of Mediterranean food: The case of Cannonau wine, myrtle berries liqueur and strawberry-tree honey. Food Chem. 2013, 140, 686-691. [CrossRef]

9. Sõukand, R.; Pieroni, A.; Biró, M.; Dénes, A.; Dogan, Y.; Hajdari, A.; Kalle, E.; Reade, B.; Mustafa, B.; Nedelcheva, A.; et al. An ethnobotanical perspective on traditional fermented plant foods and beverages in Eastern Europe. J. Ethnopharmacol. 2015, 170, 284-296. [CrossRef]

10. Matyjaszczyk, E.; Śmiechowska, M. Edible flowers. Benefits and risks pertaining to their consumption. Trends Food Sci. Technol. 2019, 91, 670-674. [CrossRef]

11. Pires, T.C.S.P.; Barros, L.; Santos-Buelga, C.; Ferreira, I.C.F.R. Edible flowers: Emerging components in the diet. Trends Food Sci. Technol. 2019, 93, 244-258. [CrossRef]

12. Schmitzer, V.; Mikulic-Petkovsek, M.; Stampar, F. Traditional rose liqueur-A pink delight rich in phenolics. Food Chem. 2019, 272, 434-440. [CrossRef]

13. Regulation (EU) 2019/787 of the European Parliament and of the Council of 17 April 2019 on the Definition, Description, Presentation and Labelling of Spirit Drinks, the Use of the Names of Spirit Drinks in the Presentation and Labelling of Other Foodstuffs, the Protection of Geographical Indications for Spirit Drinks, the Use of Ethyl Alcohol and Distillates of Agricultural Origin in Alcoholic Beverages, and Repealing. Regulation (EC) No 110/2008. Available online: http://data.europa.eu/eli/reg/ 2019/787/oj (accessed on 20 June 2021). 
14. Grunert, K.G.; Hieke, S.; Juhl, H.J. Consumer wants and use of ingredient and nutrition information for alcoholic drinks: A cross-cultural study in six EU countries. Food Qual. Prefer. 2018, 63, 107-118. [CrossRef]

15. Mohebitabar, S.; Shirazi, M.; Bioos, S.; Rahimi, R.; Malekshahi, F.; Nejatbakhsh, F. Therapeutic efficacy of rose oil: A comprehensive review of clinical evidence. Avicenna J. Phytomed. 2017, 7, 206-213.

16. Safia, A.; Aamir, Z.; Iqbal, A.; Mohamood, Z.A. Assessment of rose water and evaluation of antioxidant and anti-inflammatory properties of a rose water based cream formulation. Int. J. Pharm. Clin. Res. 2019, 11, 43-48.

17. Pires, T.C.S.P.; Dias, M.I.; Barros, L.; Ferreira, I.C.F.R. Nutritional and chemical characterization of edible petals and corresponding infusions: Valorization as new food ingredients. Food Chem. 2017, 220, 337-343. [CrossRef]

18. Cendrowski, A.; Ścibisz, I.; Mitek, M.; Kieliszek, M.; Kolniak-Ostek, J. Profile of the phenolic compounds of Rosa rugosa petals. J. Food Qual. 2017. [CrossRef]

19. Nowak, R.; Olech, M.; Pecio, L.; Oleszek, W.; Los, R.; Malm, A.; Rzymowska, J. Cytotoxic, antioxidant, antimicrobial properties and chemical composition of rose petals. J. Sci. Food Agric. 2014, 94, 560-567. [CrossRef]

20. Tabaszewska, M.; Najgebauer-Lejko, D. The content of selected phytochemicals and in vitro antioxidant properties of rose hip (Rosa canina L.) tinctures. NFS J. 2020, 21, 50-56. [CrossRef]

21. Viapiana, A.; Wesołowski, M. The phenolic contents and antioxidant activities of infusions of Sambucus nigra L. Plant Foods Hum. Nutr. 2017, 72, 82-87. [CrossRef]

22. Młynarczyk, K.; Walkowiak-Tomczyk, D.; Łysiak, G.P. Bioactive properties of Sambucus nigra L. as a functional ingredient for food and pharmaceutical industry. J. Funct. Foods 2018, 40, 377-390. [CrossRef]

23. Ferreira, S.S.; Silva, A.M.; Nunes, F.M. Sambucus nigra L. fruits and flowers: Chemical composition and related bioactivities. Food Rev. Int. 2020. [CrossRef]

24. Mahboubi, M. Sambucus nigra (black elder) as alternative treatment for cold and flu. Adv. Tradit. Med. 2020. [CrossRef]

25. Lichota, A.; Gwozdzinski, L.; Gwozdzinski, K. Therapeutic potential of natural compounds in inflammation and chronic venous insufficiency. Eur. J. Med. Chem. 2019, 176, 68-91. [CrossRef]

26. Mishra, A.; Mishra, A.; Chattopadhyay, P. Assessment of in vitro sun protection factor of Calendula officinalis, L. (Asteraceae) essential oil formulation. J. Young Pharm. 2012, 4, 17-21. [CrossRef]

27. Efstratiou, E.; Hussain, A.I.; Nigam, P.S.; Moore, J.E.; Ayub, M.A.; Rao, J.R. Antimicrobial activity of Calendula officinalis petal extracts against fungi, as well as Gram-negative and Gram-positive clinical pathogens. Complement. Ther. Clin. Pract. 2012, 18, 173-176. [CrossRef]

28. Benvenuti, S.; Bartolotti, E.; Maggini, R. Antioxidant power, anthocyanin content and organoleptic performance of edible flowers. Sci. Hortic. 2016, 199, 170-177. [CrossRef]

29. Manzor, M.; Singh, J.; Gani, A.; Noor, N. Valorization of natural colors as health-promoting bioactive compounds: Phytochemical profile, extraction techniques, and pharmacological perspectives. Food Chem. J. 2021. [CrossRef]

30. Szopa, A.; Klimek-Szczykutowicz, M.; Jafernik, K.; Koc, K.; Ekiert, H. Pot marigold (Calendula officinalis L.) —A position in classical phytotherapy and newly documented activities. Acta Sci. Pol. Hortorum Cultus 2020, 19, 47-61. [CrossRef]

31. Andersen, F.A.; Bergfeld, W.F.; Belsito, B.V.; Hill, R.A.; Klaassen, C.D.; Liebler, D.C.; Marks, J.G.; Shank, R.C.; Slaga, T.J.; Snyder, P.W. Final report of the cosmetic ingredient review expert panel amended safety assessment of Calendula officinalisderived cosmetic ingredients. Int. J. Toxicol. 2010, 29, 221S-243S. [CrossRef]

32. Chitrakar, B.; Zhang, M.; Bhandari, B. Edible flowers with the common name "marigold": Their therapeutic values and processing. Trends Food Sci. Technol. 2019, 89, 76-87. [CrossRef]

33. Takeda, K.; Osakabe, A.; Saito, S.; Furuyama, D.; Tomita, A.; Kojima, Y.; Yamadera, M.; Sakuta, M. Components of protocyanin, a blue pigment from the blue flowers of Centaurea cyanus. Phytochemistry 2005, 66, 1607-1613. [CrossRef]

34. Lockowandt, L.; Pinela, J.; Roriza, C.L. Chemical features and bioactivities of cornflower (Centaurea cyanus L.) capitula: The blue flowers and the unexplored non-edible part. Ind. Crops Prod. 2019, 128, 496-503. [CrossRef]

35. Adamczak, A.; Forycka, A.; Buchwald, W. Skład herbatek owocowych na polskim rynku artykułów spożywczych [Composition of fruit teas available on the Polish food market]. Post Fitoter 2015, 4, 216-222.

36. Pires, T.C.S.P.; Dias, M.I.; Barros, L.; Calhelha, R.C.; Alves, M.J.; Oliveira, M.B.P.P.; Santos-Buelga, C.; Ferreira, I.C.F.R. Edible flowers as sources of phenolic compounds with bioactive potential. Food Res. Int. 2018, 105, 580-588. [CrossRef]

37. Singleton, V.L.; Rossi, J.A. Colorimetry of total phenolics with phosphomolybdicphosphotungstic acid reagents. Am. J. Enol. Viticult. 1965, 16, 144-158.

38. Brand-Williams, W.; Cuvelier, M.E.; Berset, C. Use of a free radical method to evaluate antioxidant activity using the DPPH free radical method. LWT 1995, 28, 25-30. [CrossRef]

39. CIE DS 014-4.3/E:2007. Colorimétrie-Part 4: CIE 1976 L*a*b* COLOUR SPACE. Available online: http://www.unife.it/scienze/ astro-fisica/insegnamenti/ottica-applicata/materiale-didattico/colorimetria/CIE\%20DS\%2001443 (accessed on 27 October 2021).

40. Chen, G.L.; Chen, S.G.; Xie, Y.Q.; Chen, F.; Zhao, Y.Y.; Luo, C.X.; Gao, Y.Q. Total phenolic, flavonoid and antioxidant activity of 23 edible flowers subjected to in vitro digestion. J. Funct. Foods 2015, 17, 243-259. [CrossRef]

41. Li, A.N.; Li, S.; Li, H.B.; Xu, D.P.; Xu, X.R.; Chen, F. Total phenolic contents and antioxidant capacities of 51 edible and wild flowers. J. Funct. Foods 2014, 6, 319-330. [CrossRef] 
42. Chen, G.L.; Chen, S.G.; Xiao, Y.; Fu, N.L. Antioxidant capacities and total phenolic contents of 30 flowers. Ind. Crops Prod. 2018, 111, 430-445. [CrossRef]

43. Sokół-Łętowska, A.; Kucharska, A.Z.; Wińska, K.; Szumny, A.; Nawirska-Olszańska, A.; Mizgier, P.; Wyspiańska, D. Composition and antioxidant activity of red fruit liqueurs. Food Chem. 2014, 157, 533-539. [CrossRef]

44. Sidor, A.; Gamza-Michałowska, A. Advanced research on the antioxidant and health benefit of elderberry (Sambucus nigra) in food-A review. J. Funct. Foods 2015, 18, 941-958. [CrossRef]

45. Dawidowicz, A.L.; Wianowska, D.; Baraniak, B. The antioxidant properties of alcoholic extracts from Sambucus nigra L. (antioxidant properties of extracts). LWT 2006, 39, 308-315. [CrossRef]

46. Ferreira, S.S.; Silva, P.; Silva, A.M.; Nunes, F.M. Effect of harvesting year and elderberry cultivar on the chemical composition and potential bioactivity: A three-year study. Food Chem. 2020, 302, 125366. [CrossRef]

47. Vujanović, M.; Majkić, T.; Zengin, G.; Beara, I.; Tomović, V.; Šojić, B.; Đurović, S.; Radojković, M. Elderberry (Sambucus nigra L.) juice as a novel functional product rich in health-promoting compounds. RSC Adv. 2020, 10, 44805-44814. [CrossRef]

48. Ćetković, G.S.; Djilas, S.M.; Čanadanović-Brunet, J.M.; Tumbas, V.T. Antioxidant properties of marigold extracts. Food Res. Int. 2004, 37, 643-650. [CrossRef]

49. Butnariu, M.; Coradini, C.Z. Evaluation of biologically active compounds from Calendula officinalis flowers using spectrophotometry. Chem. Cent. J. 2012, 6, 2-7. [CrossRef]

50. Ercetin, T.; Senol, F.S.; Orhan, I.E.; Toker, G. Comparative assessment of antioxidant and cholinesterase inhibitory properties of the marigold extracts from Calendula arvensis L. and Calendula officinalis L. Ind. Crops. Prod. 2012, 36, 203-208. [CrossRef]

51. Dorozko, J.; Kunkulberga, D.; Sivicka, I.; Kruma, Z. The Influence of Various Drying Methods on the Quality of Edible Flower Petals. In Proceedings of the 13th Baltic Conference on Food Science FoodBalt 2019 and East European Congress on Food NEEFood. University of Life Sciences and Technologies, Jelgala, Latvia, 2-3 May 2019; Conference Materials. pp. $182-187$. [CrossRef]

52. Kishimoto, S.; Maoka, T.; Sumitomo, K.; Ohmiya, A. Analysis of carotenoid composition in petals of calendula (Calendula officinalis L.). Biosci. Biotechnol. Biochem. 2005, 69, 2122-2128. [CrossRef]

53. Escher, G.B.; Santosa, J.S.; Rosso, N.D.; Marques, M.B.; Azevedo, L.; do Carmo, M.A.V.; Daguer, H.; Molognoni, L.; do Prado-Silva, L.; Sant'Ana, A.S.; et al. Chemical study, antioxidant, anti-hypertensive, and cytotoxic/ cytoprotective activities of Centaurea cyanus L. petals aqueous extract. Food Chem. Toxicol. 2018, 118, 439-453. [CrossRef]

54. Różyło, R.; Szymańska-Chargot, M.; Gawlik-Dziki, U.; Dziki, D. Spectroscopic, mineral, and antioxidant characteristics of blue colored powders prepared from cornflower aqueous extracts. Food Chem. 2021, 346, 128889. [CrossRef]

55. Gilca, M.; Tiplica, G.S.; Salavastru, C.M. Traditional and ethnobotanical dermatology practices in Romania and other Eastern European countries. Clin. Dermatol. 2018, 36, 338-352. [CrossRef] [PubMed]

56. Pinela, J.; Carvalho, A.M.; Ferreira, I.C.F.R. Wild edible plants: Nutritional and toxicological characteristics, retrieval strategies and importance for today's socjety. Food Chem. Toxicol. 2017, 110, 165-188. [CrossRef] [PubMed]

57. Vogl, S.; Picker, P.; Mihaly-Bison, J.; Fakhrudin, N.; Atanasov, A.G.; Heiss, E.H.; Wawrosch, C.; Reznicek, G.; Dirsch, V.M.; Saukel, J.; et al. Ethnopharmacological in vitro studies on Austria's folk medicine-An unexplored lore in vitro anti-inflammatory activities of 71 Austrian traditional herbal drugs. J. Ethnopharmacol. 2013, 149, 750-771. [CrossRef] [PubMed]

58. U.S. Department of Health and Human Services; U.S. Department of Agriculture. 2015-2020 Dietary Guidelines for Americans, 8th Edition. Available online: https:/ / health.gov / dietaryguidelines/2015/guidelines/ (accessed on 21 August 2021).

59. Imark, C.; Kneubühl, M.; Bodmer, S. Occurrence and activity of natural antioxidants in herbal spirits. Innov. Food Sci. Emerg. Technol. 2001, 1, 239-243. [CrossRef]

60. Kumari, P.; Bhargava, B. Phytochemicals from edible flowers: Opening a new arena for healthy lifestyle. J. Funct. Foods. 2021, 78, 104375. [CrossRef] 